\title{
A INVESTIGAÇÃO DOUTORAL EM EDUCAÇÃO MUSICAL NO BRASIL: META-ANÁLISE E TENDÊNCIAS TEMÁTICAS DE 300 TESES
}

\author{
Doctoral research in music education in \\ Brazil: meta-analysis and thematic trends of \\ 300 theses
}

\author{
La investigación doctoral en educación \\ musical en Brasil: metaanálisis y tendencias \\ temáticas de 300 tesis
}

\author{
ELITON PeRPÉtuo Rosa PeREIRA \\ Instituto Federal de Goiás - Brasil \\ eliton.pereira@ifg.edu.br \\ CAROL Gillanders \\ Universidade de Santiago de Compostela - Espanha \\ carol.gillanders@usc.es
}

\begin{abstract}
Resumo: O objetivo desta pesquisa é analisar o desenvolvimento da educação musical como um campo científico no Brasil. Encontramos 300 teses que abordam temas diretamente relacionados à educação musical, de 1989 até 2017. Esta investigação de estado da arte contém aspectos documentais, quantitativos e qualitativos e foi desenvolvida por meio das técnicas de análise de conteúdo. Como resultados, apresentamos um mapeamento descritivo de categorias, como gênero, evolução do índice de produção, áreas de produção, universidades, contexto educativo, subtemáticas, didáticas da música, e ainda as linhas investigativas da área que configuram os temas de interesse da pesquisa em educação musical no Brasil. Além destas sinteses descritivas, também apresentamos formas de acesso a três produtos originados da investigação: 1) Formulários com categorias de análise; 2) Galerias de mapas e imagens descritivas da produção; 3) Índices e catálogo das 300 teses.
\end{abstract}

Palavras-chave: Educação musical. Brasil. Teses. Meta-análise.

\begin{abstract}
The aim of this research is to analyse the development of music education as a scientific field in Brazil. We found 300 theses that deal with themes directly related to music education, from 1989 to 2017. This state-of-the-art investigation contains documentary, quantitative and qualitative aspects and was developed through content analysis techniques. As results, we present a descriptive mapping of categories such as gender, evolution of production index, production areas, universities, educational context, subthemes, music didactics, as well as the research lines of the area that configure themes of interest in music education research in Brazil. In addition to these descriptive syntheses we also present ways of accessing the three products originated from the research: 1) Forms with categories of analysis; 2) Map galleries and descriptive images of production; 3) Indexes and Catalog of 300 theses.
\end{abstract}

Keywords: Music Education. Brazil. Theses. Meta-Analysis.

Resumen: El objetivo de esta investigación es analizar el desarrollo de la educación musical como campo científico en Brasil. Encontramos 300 tesis que abordan temas directamente relacionados con la educación musical, de 1989 a 2017. Esta investigación de 'estado del arte' contiene aspectos documentales, cuantitativos y cualitativos y se desarrolló utilizando técnicas de análisis de contenido. Como resultado, presentamos un mapeo descriptivo de categorias, como género, evolución del índice de producción, áreas de producción, universidades, contexto educativo, subtemática, didáctica de la música, así como las líneas de investigación del área que configuran los temas de interés en la investigación en educación musical en Brasil. Además de las sintesis descriptivas, también presentamos formas de acceder a tres productos de investigación: 1) formularios con categorias de análisis; 2) Mapa de galerías e imágenes descriptivas de la producción; 3) Îndices y catálogo de las 300 tesis.

Palabras clave: Educación musical. Brasil. Tesis. Metaanálisis. 


\section{INTRODUÇÃO}

No Brasil, o desenvolvimento da educação musical como área de conhecimento está atrelado ao transcurso histórico e cultural da nação, aos processos de democratização nos âmbitos político e social, e ao desenvolvimento do campo científico da Educação, do campo da Música e da pesquisa em educação musical propriamente dita (Fernandes, 2007; DelBen, 2013; Tomás, 2015). Tais avanços, juntamente com o fortalecimento dos conservatórios, e com a luta pela presença da música na escola de educação básica, se somaram ao surgimento de programas de pósgraduação que admitem investigações em educação musical (Pereira, 2017, 2019).

Partindo deste contexto social e histórico, verificamos que a pesquisa stricto sensu em educação musical avançou a um nivel que os pesquisadores brasileiros não conseguiram dar continuidade ao acompanhamento do desenvolvimento quantitativo da produção da área, como vinha sendo feito por Del-Ben (2010, 2013), Fernandes (2000, 2007), Araújo e Toscano (2013) e Pires e Dalben (2013), principalmente.

Partindo destes estudos prévios, lançamos mão de uma incursão histórico-social e documental sobre a área, a qual foi desenvolvida conjuntamente por meio do acesso a 300 teses de doutoramento, usadas em uma análise quantitativa e qualitativa com base em categorias previamente encontradas na revisão dos estudos já desenvolvidos com o mesmo objetivo.

O objetivo geral desta investigação foi analisar o desenvolvimento da educação musical como campo científico no Brasil por meio das produções derivadas dos projetos de investigação de doutoramento. Entre os objetivos específicos, listamos:

- Realizar uma busca sobre a investigação em educação musical a partir de meados do século XX em fontes de documentação científica;

- Elaborar formas de organização para acesso aos resultados da investigação doutoral em educação musical do Brasil;

- Estabelecer o marco atual dos temas de interesse da investigação em educação musical que podem se constituir em linhas de investigação da área.

\section{METODOLOGIAS INTEGRADAS NA INVESTIGAÇÃO}

Esta é uma pesquisa de estado da arte de base bibliográfica e documental com abordagem metodológica quantitativa e qualitativa.

O estudo foi construído com base em uma revisão sistemática de literatura (Cooper, 2009) com emprego de técnicas de análise de conteúdo, com base nas indicações metodológicas de Bardin (2011), Franco (2012), e 
Bauer e Gaskell (2013), que orientam o trabalho de análise por classificação e categorização em pesquisa bibliográfica/documental. Além da análise de conteúdo, a investigação exigiu a integração de várias metodologias afins, como o estado da arte e a meta-análise.

O estado da arte ou estado da investigação ${ }^{1}$, como estudos de revisão sistemática da produção científica, apresenta várias abordagens e procedimentos que são adotados conforme a natureza específica de cada estudo, que pode ser macro ou micro, por área, por subárea ou ainda por recortes mais específicos.

O trabalho de Vosgerau e Romanowski (2014) apresenta uma análise dos tipos de estudos envolvidos com as pesquisas de estado da arte. Os autores destacam nomenclaturas, identificações e procedimentos metodológicos com base em exemplos de pesquisas concretas. No entanto, apesar de citarem as tipologias de revisões sistemáticas, dão a entender que todo o arcabouço se aglomera no eixo intitulado "Estudos de revisão".

A expressão "estado da arte" nem sempre está ligada a um trabalho de revisão sistemática, podendo significar o estado mais elevado de uma tecnologia ou área de conhecimento, e este sentido também não está ausente do seu emprego nas pesquisas específicas de revisão de literatura científica, como explicam as normas da Associação Americana de Psicologia:

O estado da arte vem originalmente do campo da pesquisa técnica, científica e industrial e significa, em poucas palavras, a situação de uma determinada tecnologia. O mais inovador ou o recente em relação a uma arte específica. Esta noção passou a estudos de pesquisa acadêmica como "o status ou a situação de um tópico no presente". É uma maneira de se referir ao que é conhecido sobre um problema, o que foi dito até agora que tem sido mais relevante ${ }^{2}$ (APA, 2017, p. 1).

As normas da Associação Americana de Psicologia (APA, 2017) esclarecem que, na área de estudos acadêmicos, o estado da arte refere-se à construção de um tipo de análise documental. Isto com o objetivo de mostrar os avanços mais importantes em relação ao conhecimento de uma determinada temática.

Assim, a abordagem quantitativa ou mista está muito presente nos estudos de estado da arte, de modo que a meta-análise, desde o contexto da pesquisa norte-americana (Cooper, Hedges; Valentine, 2009; Hunter;

\footnotetext{
${ }^{1}$ Aqui tidos como sinônimos, mas não desconsiderando as definições específicas de cada pesquisador. Para Weiss (2005), "estado do conhecimento é uma análise sistemática e valorativa da produção científica". López e Mota (2003) explicam que o "estado da investigação busca compreender o contexto sociocultural da produção: os grupos de pesquisadores, sua formação e condições de trabalho, os programas de pesquisa. Incluindo [...] diagnósticos e panoramas relacionados à reflexão epistemológica, metodológica e impacto da investigação" (Londoño Palacio; Maldonado Granados; Calderón Villafáñez, 2014, p. 18-19, tradução nossa).

${ }^{2}$ Normas APA. Tradução nossa. Disponível em: http://normasapa.net/que-es-el-estado-del-arte. Acesso em: dez. 2017.
} 
Schmidt, 2004), se constitui em um sinônimo de revisão sistemática e de estado da arte.

No contexto da pesquisa em Educação, o conceito metodológico de meta-análise foi usado pela primeira vez por Glass (1976) em um artigo publicado na revista Educational Researcher para designar "a análise estatística de uma grande coleção de resultados de análises de estudos individuais com o propósito de integrar os achados" (Glass apud Urso Junior, 2011, p. 26).

Mais recentemente, no contexto das revisões sistemáticas de literatura, os estudos empregam abordagens quantitativas e qualitativas. A abordagem quantitativa se deu inicialmente no contexto da pesquisa científica norteamericana, mas, conforme apareceu a necessidade de comparar resultados de pesquisas qualitativas, essa abordagem foi ampliada para os estudos do contexto das ciências sociais, chegando ao que alguns autores chamam de meta-análise qualitativa. $\mathrm{Na}$ meta-análise qualitativa, o grande diferencial são as análises de dados que se dão de modo textual, conceitual e discursivo/interpretativo. Assim, os trabalhos de Del-Ben (2010), Lovatto et al. (2007) e Rodrigues (2002) são exemplos de estudos desenvolvidos no Brasil que se orientam metodologicamente por meta-análises qualitativas.

A análise de conteúdo contribui, nesse contexto, por ser uma conceituada metodologia que contém uma grande variedade de procedimentos metodológicos com abrangente aplicação em diversos tipos de pesquisas quantitativas e/ou qualitativas. Bardin (2011) e Franco (2012) vão igualmente defender que a análise deve ser antecedida pelo desenvolvimento de um plano de investigação que integre processos de seleção e amostra de dados, eleição de categorias de conteúdo e unidades de registro a serem enquadradas nas categorias. É desta estrutura geral, e não somente do processo de análise, que provém a qualidade deste tipo de estudo, que deve buscar comparações entre as categorias e as classes de inferência que podem ser extraídas dos dados.

\section{DESENHO DA INVESTIGAÇÃO}

A pesquisa é desenvolvida por meio de procedimentos explicitados anteriormente - estado da arte, meta-análise, análise de conteúdo. No contexto da revisão sistemática de literatura, temos as pesquisas de estado da arte. Os procedimentos das análises de conteúdos constituíram as metaanálises qualitativas junto às teses ou artigos correspondentes da área da educação musical no Brasil.

\section{Fases da investigação}

Inicialmente, a investigação construiu um marco teórico que veio a contribuir para a elaboração de instrumentos de análise - como suporte para categorias e indicadores de referência. Posteriormente, procederemos 
ao levantamento de dados junto às trezentas (300) teses brasileiras. E, ainda, realizaremos as análises descritivas vinculadas aos dados e aos contextos em que foram constituídos. Essas etapas podem ser apresentadas em dez fases distintas:

- Teorias desenvolvidas nos capítulos dão suporte para a criação de formulários de análise de conteúdo;

- Elaboração dos formulários durante a escrita do marco teórico;

- Avaliação dos formulários por especialistas com revisão das categorias;

- Levantamento de uma lista de teses da área da educação musical a partir do site da Capes ${ }^{3}$ - Plataforma Sucupira - Brasil;

- Coleta de teses nos links da Plataforma Sucupira ou de artigos correspondentes às teses não encontradas, via consulta ao Currículo Lattes ${ }^{4}$ dos pesquisadores doutores;

- Aplicação dos formulários nas teses ou artigos equivalentes;

- Organização de estatísticas descritivas em gráficos e tabelas por categorias;

- Análise descritiva das categorias de análise temática e conceitual das teses e reelaboração dos indicadores das principais categorias;

- Elaboração de sinteses, inferências, cartografias e esboços conclusivos;

- Elaboração de produtos, como o catálogo de teses da área no Brasil.

\section{Fontes: critérios de seleção e fichamento}

As fontes, ou unidades de análise (Franco, 2012), foram as 300 teses sobre educação musical desenvolvidas no Brasil ${ }^{5}$ em programas de pósgraduação em Educação ou Música ou em outra área, desde que disponiveis on-line, identificadas via listagem de cadastro no site do MEC/Brasil (Plataforma Sucupira) e encontradas nas bibliotecas das universidades brasileiras. Nesse estudo acessamos 33 sites de bibliotecas universitárias brasileiras.

No caso de teses não encontradas, foram buscados artigos publicados em revistas científicas brasileiras, desde que correspondentes à temática

\footnotetext{
${ }^{3}$ Capes - Coordenação de Aperfeiçoamento de Pessoal de Nível Superior do MEC (Ministério da Educação do Brasil). A Plataforma Sucupira (de teses brasileiras) pode ser acessada no site: https://sucupira.capes.gov.br/sucupira/.

${ }^{4}$ Os currículos dos autores das teses podem ser acessados em uma plataforma brasileira - Plataforma Lattes: http://buscatextual.cnpq.br/buscatextual.

${ }^{5}$ Os arquivos em PDF das 300 teses foram transportados para o software de gestão de referências Mendeley e organizados em ordem alfabética por nome do(a) autor(a).
} 
central da tese listada no cadastro da Plataforma Sucupira (MEC/Brasil). Os artigos foram identificados no Currículo Lattes dos pesquisadores doutores, de acordo com a lista de teses da área.

Houve também a análise dos currículos (Currículo Lattes) dos pesquisadores da área da educação musical para identificação da produção científica relacionada à cada tese. Nessa última análise, foram realizados estudos estatísticos cienciométricos da produção da área.

\section{Coleta de dados: recorte temporal e amostra}

Os dados foram extraídos das teses por meio dos quatro formulários de análise de conteúdo elaborados exclusivamente para esta pesquisa6 ${ }^{6}$.

O recorte temporal da pesquisa abarca quase trinta anos de produção doutoral disponivel on-line, sendo possível acessar teses brasileiras sobre educação musical, das quais a mais antiga foi defendida em 1989. O estudo cobre praticamente a totalidade do período de produção doutoral da área no Brasil, até 2017.

O recorte geográfico diz respeito somente à produção nacional, ou seja, teses defendidas em programas brasileiros de doutoramento, estudos que podem advir de universidades públicas ou privadas, e ainda de qualquer campo de conhecimento, com especial atenção para os campos da Educação e da Música.

Assim, a amostra equivale à totalidade das fontes elegiveis como unidades de registro para análise da produção nacional da área.

\section{Análise de dados}

Criamos quatro formulários de análise para identificação e classificação temática. A codificação dos textos ocorreu em dois momentos diferentes, no uso de uma tabela de classificação e, posteriormente, em um software de análise qualitativa 7 . Os indicadores das categorias estão presentes nos referenciais de cada formulário, pois cada um foi elaborado com base em autores específicos e em pesquisas previamente desenvolvidas.

O Formulário 1, apresentado a seguir, foi aplicado com o objetivo de identificar os trabalhos, realizar uma pré-análise e organização dos dados em uma tabela específica de classificação. Além de possibilitar uma identificação dos atributos de identidade da tese, o Formulário 1 também apresenta uma classificação por nivel de ensino, pesquisando, na tese, modalidade e ambiente educativo. Outra categoria identificada neste primeiro formulário é a linha investigativa - dentre 18 linhas previamente elencadas.

\footnotetext{
6 Apresentados no Apêndice $\mathrm{B}$ da tese, acessível no site (Produtos, Apêndices e Anexos): https://sites.google.com/view/educacaomusicalnobrasil.

7 Software NVivo 11. O NVivo pertence ao grupo de softwares para Qualitative Solutions Research (QSR), sendo um software elaborado para análise descritiva e qualitativa de dados.
} 
1 Autor

3 Ano de defesa

5 Orientador(a)

7 Cidade

9 Nivel de ensino estudado

10 Modalidade estudada

11 Ambiente estudado
IDENTIFICAÇÃO GERAL

2 Gênero

4 Título do trabalho

6 Universidade

8 Área: ( ) Música ( ) Educação ( ) Outro. Qual:

( ) Bebês ( ) Ed. Infantil ( ) Ed. Básica - fund./médio

( ) Técnico () Superior ( ) Pós-Graduação lato sensu

( ) Mestrado () Doutorado e pós-Dr. () Não se aplica

( ) Ens. Presencial ( ) Ens. a distância ( ) EJA ( )

Especial

( ) Quilombola ( ) Outro. Qual: ( ) Não se aplica

() Ensino Formal ( ) Escola de ensino específico

( ) Ensino informal/não formal ( ) Outro. Qual:

() Não se aplica

12 Link do currículo do autor

13 Quantidade de publicações com base na tese

() Tese () Registro em biblioteca com resumo

( ) Artigo para tese não encontrada ( ) Sem link

14 Link Web (PDF ou sem link)

( ) História da educação musical

? ( ) Filosofia da educação

musical

( ) Performance e técnica

instrum./vocal

( ) Métodos ativos

( ) Construtivismo, Cognição e

Psicologia

( ) Propostas críticas

() Currículo e Didática

( ) Políticas públicas e legislação

( ) Formação de prof. e assoc. de classe

( ) Escola de ensino básico e educação formal

( ) Multiculturalismo e Música no cotidiano

( ) Novas tecnologias, virtualidade e aprendizagem em rede

( ) Gênero, raça, minorias e ecologia

( ) Educação musical especial e inclusiva

( ) Musicalização de bebês e educação musical infantil

() Educação de adultos e terceira idade

() Interartes e interáreas

( ) Revisão da produção científica em

educação musical

Formulário 1: Identificação da tese e relação com divulgação científica. Fonte: Elaborado com base em Libâneo, Oliveira e Toschi (2012) e Souza e Magalhães (2011). Nota: Descritores de identificação criados para esta pesquisa com base nos recortes temporais e geográficos.

Os Formulários 2 e 3, apresentados a seguir, são compostos de categorias de identificação de temáticas pré-estruturadas. Estes formulários foram desenvolvidos a partir das investigações de Gillanders e Martínez Casillas (2005) e Oriol de Alarcón (2012). O Formulário 2 apresenta duas possibilidades de classificação de categorias vinculadas à Educação em geral, a primeira ligada ao contexto intrínseco ao processo de ensino/aprendizagem (2i), e a segunda ligada ao contexto extrínseco ao processo de ensino/aprendizagem (2e). É importante ressaltar que nem sempre as pesquisas da área abordam temas relacionados ao processo ensino/aprendizagem propriamente dito. 


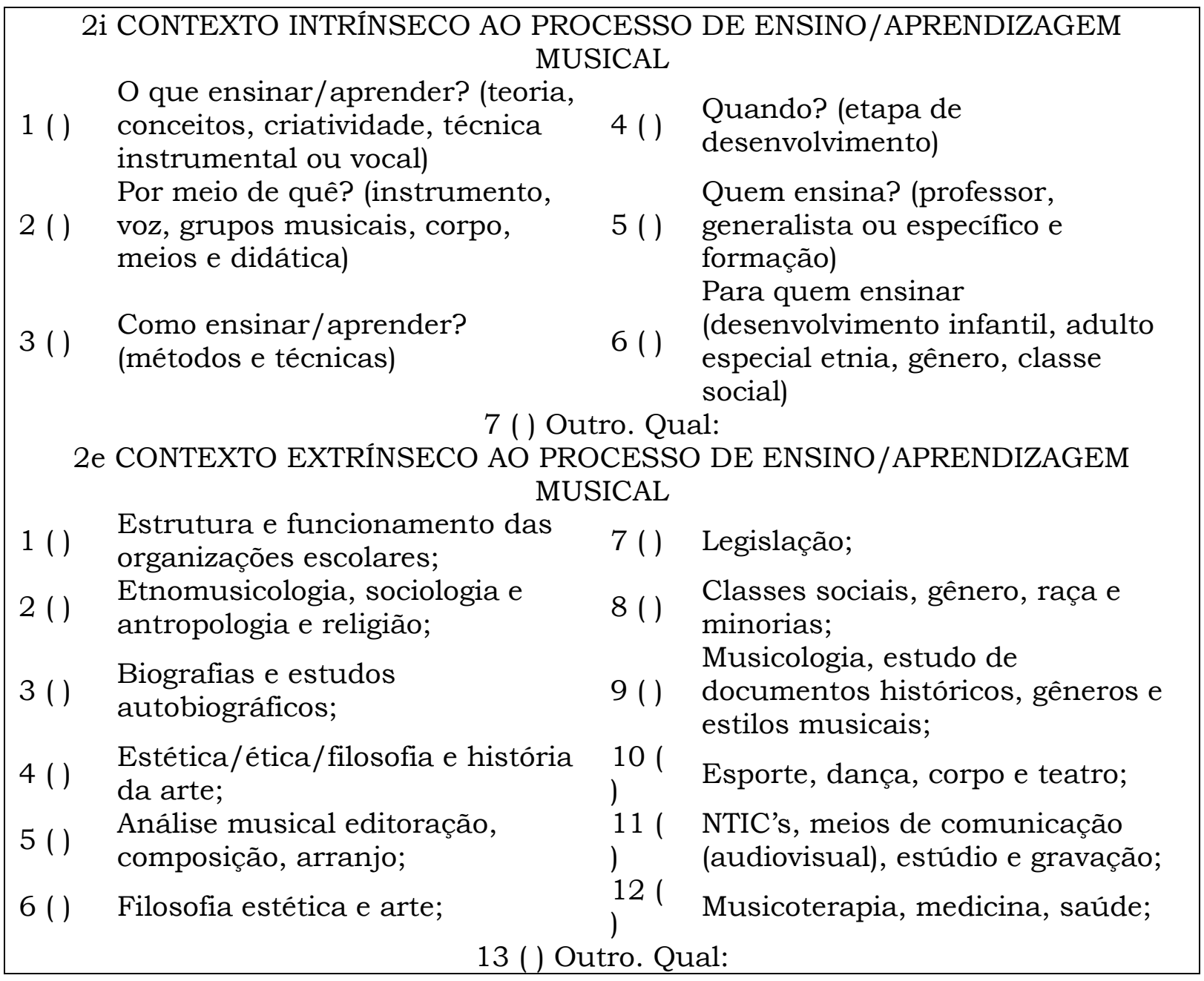

Formulário 2: Análise das temáticas gerais da educação musical (múltipla escolha). Fonte: Baseado em Gillanders e Martinez Casillas (2005) e Oriol de Alarcón (2012).

O Formulário 3, a seguir, apresenta subtemas exclusivos da área da educação musical. Ambos os formulários são de múltiplas escolhas e serviram para dar suporte à uma análise geral das temáticas por meio de codificações realizadas nos títulos, resumos e palavras-chaves das teses. 


\begin{tabular}{|c|c|c|c|}
\hline 1() & $\begin{array}{l}\text { Instrumento musical, grupos } \\
\text { musicais (voz e coro); }\end{array}$ & 12() & $\begin{array}{l}\text { Métodos e técnicas de ensino de } \\
\text { música (didática); }\end{array}$ \\
\hline 2() & $\begin{array}{l}\text { Performance musical - } \\
\text { interpretação (instrumental ou } \\
\text { vocal ou coletiva); }\end{array}$ & 13() & $\begin{array}{l}\text { Novas tecnologias e meios } \\
\text { audiovisuais; }\end{array}$ \\
\hline 3() & $\begin{array}{l}\text { Conceptualização teórica e/ou } \\
\text { elementos do som (acústica, } \\
\text { leitura e escrita); }\end{array}$ & 14() & $\begin{array}{l}\text { Legislação (normativas e definições } \\
\text { coletivas); }\end{array}$ \\
\hline 4() & $\begin{array}{l}\text { Cognição, psicologia, } \\
\text { psicopedagogia (processos de } \\
\text { desenvolvimento); }\end{array}$ & 15() & $\begin{array}{l}\text { Intervenção educativa, avaliação e } \\
\text { reformas; }\end{array}$ \\
\hline 5() & $\begin{array}{l}\text { Concertos didáticos, percepção e } \\
\text { apreciação; }\end{array}$ & 16() & $\begin{array}{l}\text { Sociologia, etnomusicologia, } \\
\text { interculturalidade e } \\
\text { multiculturalismo, folclore; }\end{array}$ \\
\hline 6() & $\begin{array}{l}\text { Criatividade, criação e } \\
\text { composição, improvisação; }\end{array}$ & 17() & $\begin{array}{l}\text { Dança, cena, corpo, movimento } \\
\text { (interartes); }\end{array}$ \\
\hline 7() & $\begin{array}{l}\text { Currículo (discussão curricular } \\
\text { em vários níveis); }\end{array}$ & 18() & $\begin{array}{l}\text { Música litúrgica, religiosa ou com } \\
\text { função cívica; }\end{array}$ \\
\hline 8() & Professores (formação e prática); & 19() & $\begin{array}{l}\text { Documentos, manuscritos, } \\
\text { impressão e publicação; }\end{array}$ \\
\hline 9 ( ) & Educação especial; & 20() & Gênero e minorias; \\
\hline 10() & Autores, biografias; & 21() & História da pedagogia musical. \\
\hline 11() & $\begin{array}{l}\text { Recursos materiais/recursos } \\
\text { pedagógicos, livros; }\end{array}$ & 22() & Outro. Qual: \\
\hline
\end{tabular}

Formulário 3: Análise de subtemas específicos da educação musical (múltipla escolha). Fonte: Baseado em Gillanders e Martínez Casillas (2005) e Oriol de Alarcón (2012).

O Formulário 4, apresentado a seguir, foi estruturado em oito categorias de identificação de didáticas predefinidas a partir dos trabalhos de Fernandes (2013), Hemsy de Gainza (1998), Loureiro (2003, 2004) e Mateiro (2006).

1 ( ) Tradicional (história e filosofia);

2 ( ) Tecnicista (teorizante, focada na leitura e escrita e na técnica instrumental/vocal estritamente);

3 ( ) Metodológica (métodos instrumentais/vocais não estritamente técnicos);

4 ( ) Ativa (escola nova, construtivismo, métodos ativos, eutonia, Gestalt);

5 ( ) Cognitivista (inteligência, psicologia do desenvolvimento e da aprendizagem socioconstrutivismo);

6 ( ) Criativa (oficinas, improvisação, composição, criação, experimentação);

7 ( ) Sociocrítica (movimentos sociais, socioculturais, valorização da classe social, marxismo, teoria crítica);

8 ( ) Contextualista, culturalista, pós-moderna (pós-estruturalismo, gênero, minorias, desconstrução etc.).

9 () Outro. Qual: Definir/Explicar.

Formulário 4: Análise de didáticas musicais. Fonte: Com base em Fernandes (2013), Hemsy de Gainza (1998), Loureiro (2003, 2004) e Mateiro (2006). 
As teses da área da educação musical foram buscadas em três bases de dados nacionais, oficialmente desenvolvidas pelo governo brasileiro:

- Catálogo de teses da Capes: www.catalogodeteses.capes.gov.br

- Biblioteca Digital Brasileira de Dissertações e Teses: www.bdtd.ibict.br

- Portal Domínio Público: www.dominiopublico.gov.br

O descritor de busca usado foi a expressão "educação musical" (entre aspas). Algumas teses apareceram em diferentes bases de dados, tornando a busca mais difícil, porém acredita-se que a amostra coletada seja equivalente à totalidade de trabalhos de teses defendidas no Brasil com esta temática até o ano de 2017.

Em muitos casos não encontramos os arquivos digitais das teses nos sites das 33 universidades brasileiras identificadas, de forma que foi necessário entrar em contato por e-mail com vários pesquisadores, cujos dados foram acessados na plataforma Lattes, site que contém os currículos dos pesquisadores do Brasil. Em alguns poucos casos, consideramos textos de apresentação de livros correspondentes às teses, isto por não encontrar artigo científico relacionado ou cadastro bibliotecário da tese. A acessibilidade aos arquivos completos das teses em PDF se deu por meio dos sites das bibliotecas das universidades brasileiras.

Um total de 264 teses foram encontradas em formato PDF, 13 com disponibilidade no registro bibliotecário, 19 das quais foram encontradas em artigos científicos ou em apresentações de livros oriundos das teses; e ainda outras quatro das quais não foi encontrada informação on-line de nenhuma natureza.

Os processos de referenciação, classificação e codificação deste volume de teses doutorais se deram a partir dos seguintes passos:

- Criação de uma lista geral das teses identificadas com temas ou problemáticas de investigação diretamente ligadas à educação musical;

- Organização dos PDFs das teses no gestor de referências Mendeley (Elsevier):

- www.mendeley.com;

- Organização das classificações no software de planilhas Excel (Microsoft):

- www.products.office.com; ou Open Office: www.openoffice.org;

- Importação das planilhas de classificação para o software NVivo (QSR Internacional): www.qsinternational.com/NVivo/home;

- Exploração do índice de publicações e citações por meio do software Publish or Perish (Anne-Wil Harzing): www.harzing.com. 


\section{RESULTADOS: META-ANÁLISE E TEMÁTICAS DAS TESES}

Apresentamos os resultados descritivos das análises quantitativas juntamente com a exposição de comentários sobres os dados em relação aos trabalhos anteriores que desenvolveram revisões sobre a produção científica em educação musical e em relação aos autores que deram origem às categorias presentes nos formulários.

No Gráfico 1, a seguir, é possivel verificar a ampliação do índice de produção ao longo de 27 anos de pesquisa doutoral em educação musical no Brasil. Na primeira década foram produzidas somente onze teses (19891999) ${ }^{8}$, na segunda já comparecem mais 65 teses (2000-2008), e na última década (2009-2017) foram defendidas 222 teses.

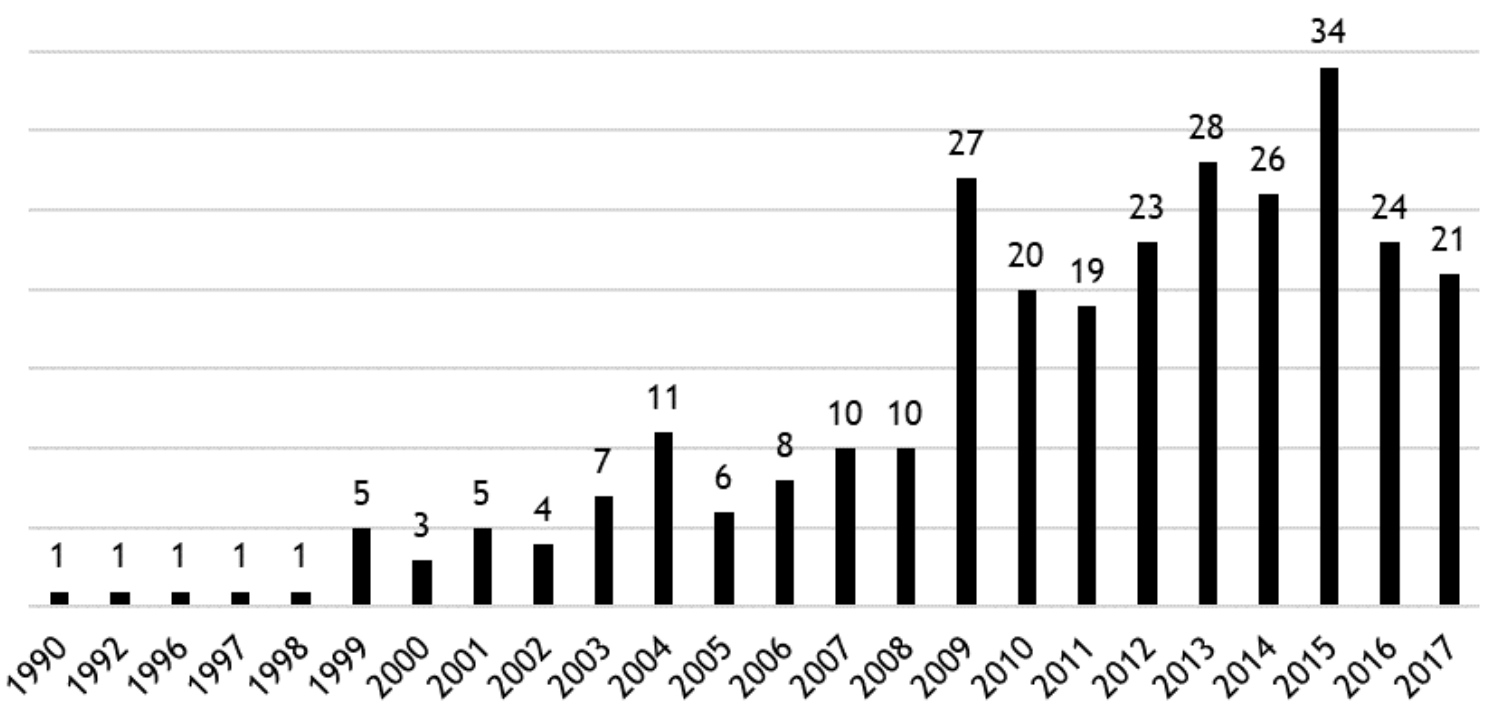

Gráfico 1: Ampliação da produção doutoral em educação musical no Brasil (1990-2017). Fonte: Elaborado pelo autor. Análise de dados da investigação junto às 300 teses.

Em relação ao gênero dos(as) autores(as), identificamos $62,37 \%$ das teses desenvolvidas pelo gênero feminino e $37,63 \%$ pelo gênero masculino. Observa-se, no Gráfico 2, que a linha investigativa mais pesquisada nas teses é a formação de professores (9), majoritariamente investigada pelo gênero feminino ( $\mathrm{F}$ 9). Outras quatro linhas investigativas também são majoritariamente estudadas por mulheres: gênero, raça e minorias (13); educação musical especial (14); musicalização de bebês (15); educação de adultos (16). O Gráfico 9, apresentado mais à frente, apresenta mais claramente as 18 linhas investigativas identificadas na produção científica da área.

\footnotetext{
${ }^{8}$ Entre as quatro teses não incluídas na análise, está a primeira tese desenvolvida na área, de 1989, à qual tivemos acesso somente após as análises: Moraes (1989).
} 


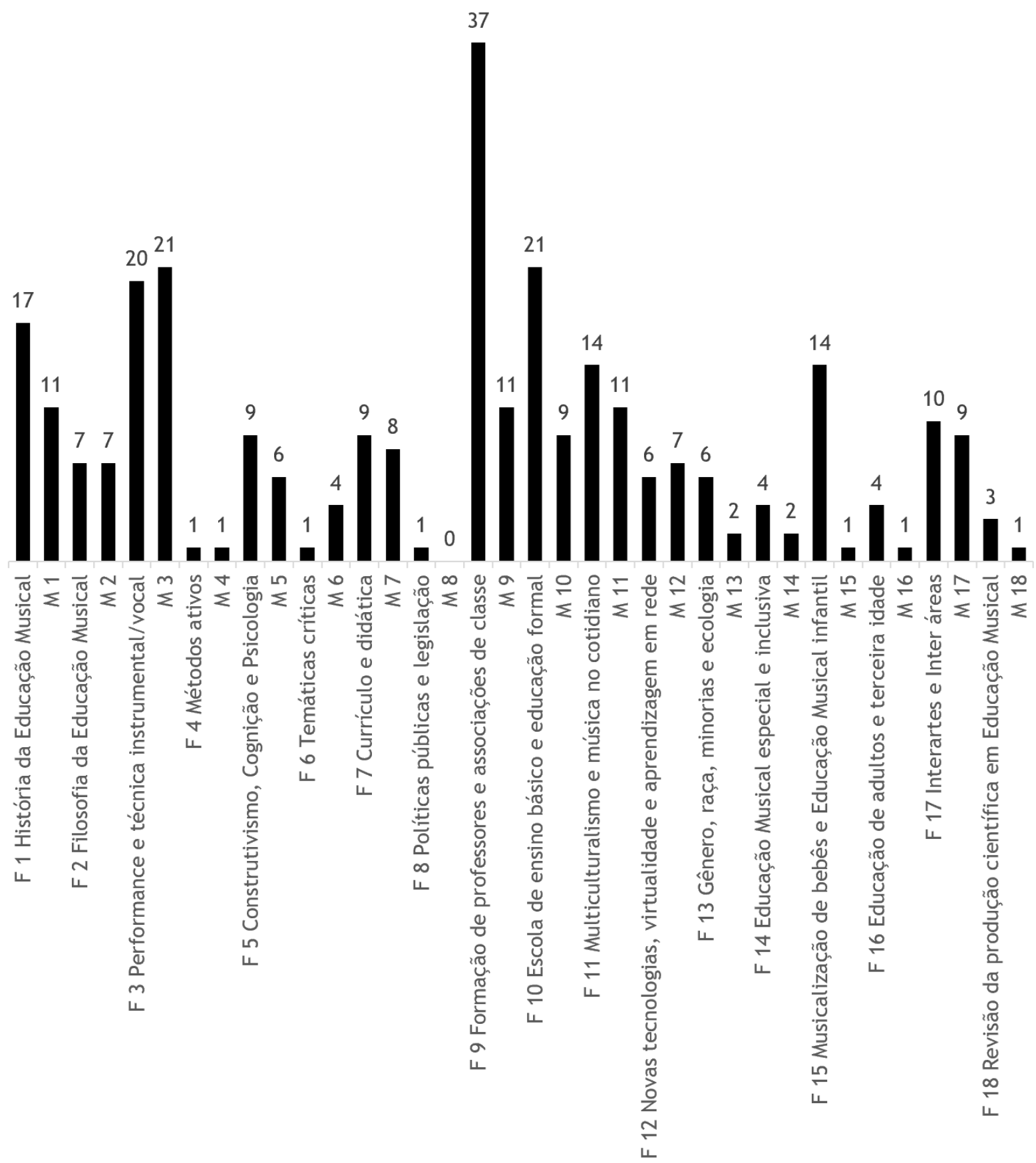

Gráfico 2: Gênero por linhas investigativas e quantitativo de teses

(Formulário 1). Fonte: Elaborado pelo autor. Análise de dados da investigação junto às 300 teses. Legenda: $\mathrm{F}=$ Feminino; $\mathrm{M}=$ Masculino.

O Gráfico 3 mostra o quantitativo de teses por área de conhecimento. Verifica-se que as teses brasileiras são desenvolvidas nos programas de Doutorado em Música e Doutorado em Educação, seguidos por mínima participação de outras áreas, como Artes, Psicologia, Medicina, Educação Ambiental, Comunicação e Semiótica. Esses dados confirmam os dados levantados até 2007 por Fernandes (2000, 2007). 


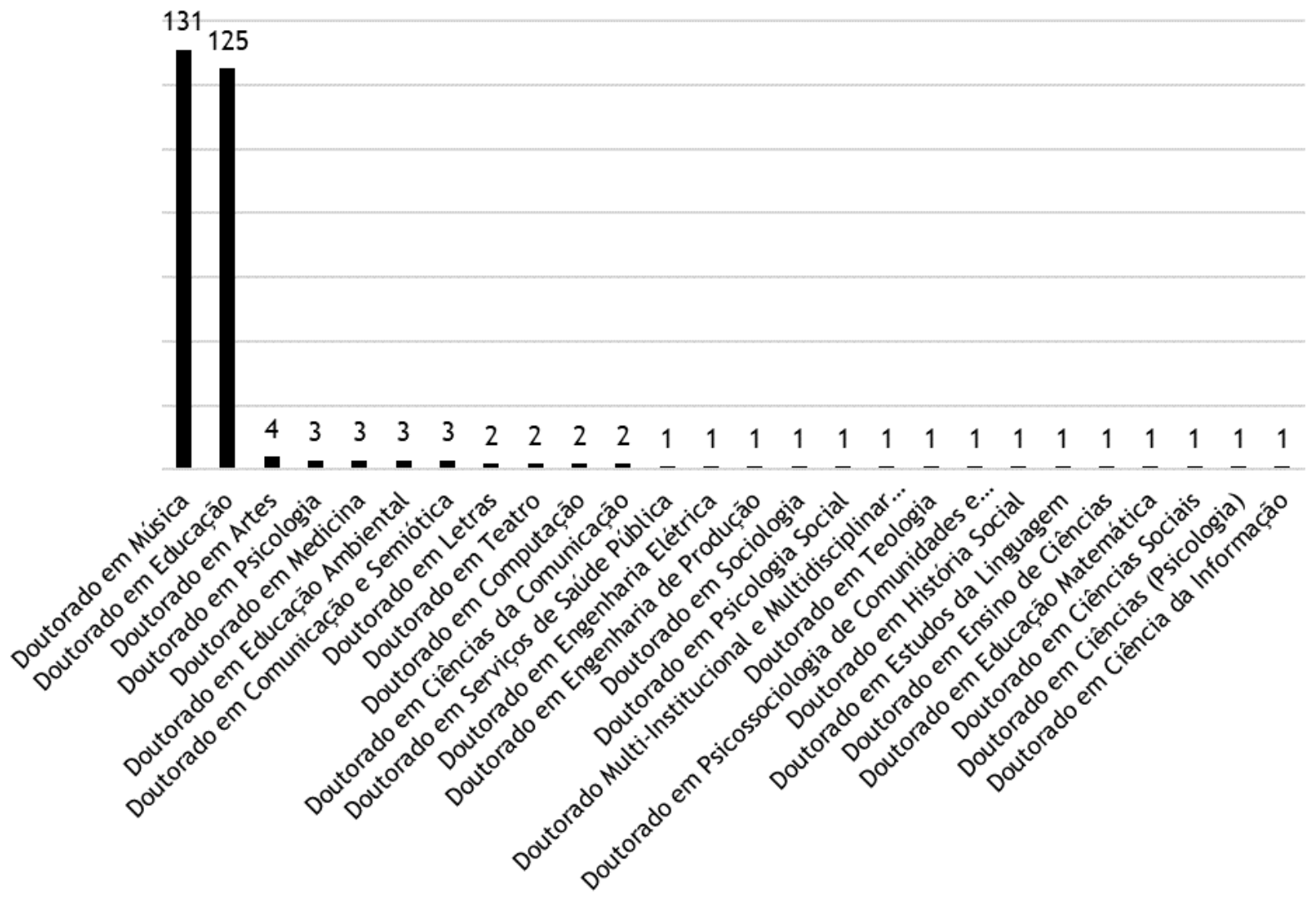

Gráfico 3: Área de conhecimento por quantidade de teses (Formulário 1). Fonte: Elaborado pelo autor. Análise de dados da investigação junto às 300 teses.

No Gráfico 4, é possível visualizar a quantidade geral de fontes por quantidade de publicações referentes às teses. É necessário destacar que mais de 40 teses não geraram nenhum tipo de publicação científica referente ao trabalho doutoral, grupo que majoritariamente optou por comunicações em anais de congressos. Mais de 150 investigadores publicaram de um a quatro artigos ou livros. Cerca de 50 investigadores publicaram de 5 a 10 artigos, e somente 20 pesquisadores publicaram mais de 10 artigos ou livros oriundos do trabalho de tese.

Macias-Chapula (1998) explica o papel das análises cienciométricas na compreensão do desenvolvimento da produção científica. No caso da produção doutoral em educação musical, a média da produção por autor é de quatro publicações com base na investigação doutoral. 


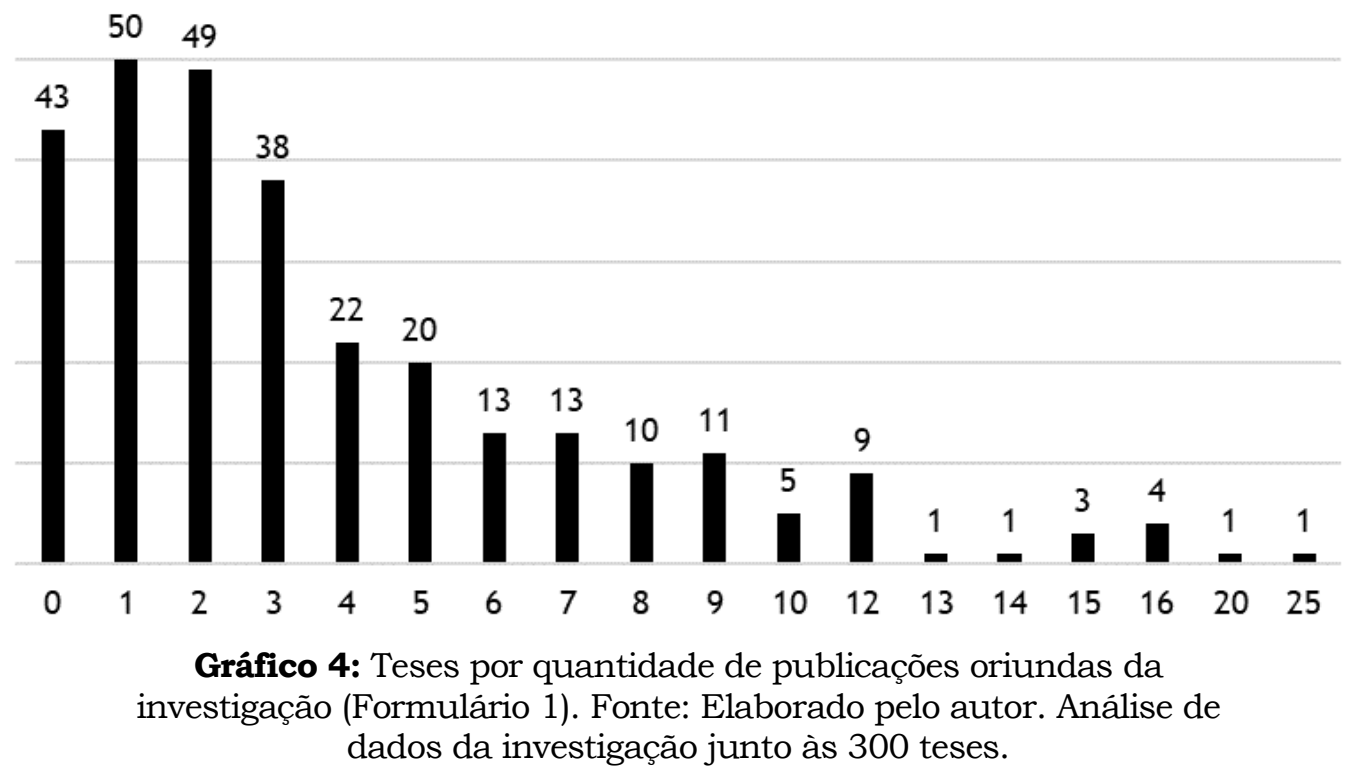

O Gráfico 5 apresenta o quantitativo de teses por universidades brasileiras. Destacam-se as universidades das regiões Nordeste, Sul e Sudeste do Brasil. Nota-se que, entre as universidades que mais produzem na área, somente uma é privada, e as demais são públicas. De 33 universidades com produção na área, somente 8 são privadas. Foram criados mapas $^{9}$ que apresentam a distribuição das universidades que orientam pesquisas doutorais no território brasileiro.

\footnotetext{
${ }^{9}$ Mapas on-line nos quais se pode verificar a distribuição das universidades brasileiras com teses da área: https://drive.google.com/open?id=1AuoejWgOATHjgGarpL2HGac9edbwyOCj\&usp=sharing (maio 2018); https://www.easymapmaker.com/map/0b6821af03cdbf42f73d5760c713e5b0 (maio 2018).
} 


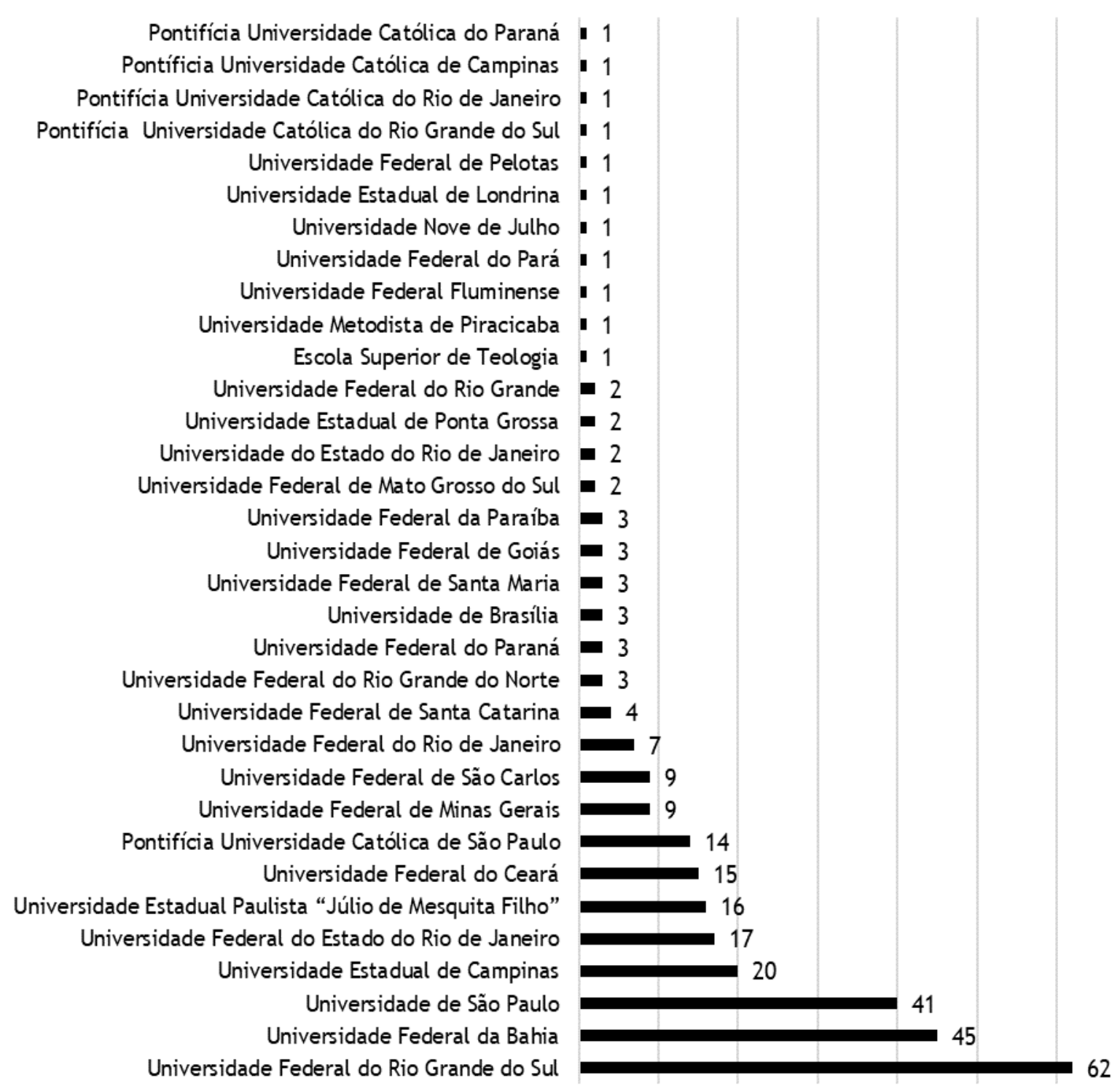

Gráfico 5: Teses em educação musical em 33 universidades (Formulário 1). Fonte: Elaborado pelo autor. Análise de dados da investigação junto às 300 teses.

Além dessa relação, como veremos a seguir, ainda identificamos o "ambiente educacional" (formal, específico de música ou informal). Identificamos também as "modalidades educativas" (presencial, EAD, especial, EJA, indígena ou quilombola) ${ }^{10}$. E ainda o "nivel de ensino" (bebês, infantil, fundamental, médio, técnico, superior, pós-graduação lato sensu, mestrado e doutorado).

Estas três categorias dizem respeito somente às teses que investigam as relações intrínsecas ao processo de ensino-aprendizagem. $\mathrm{O}$ ambiente

${ }^{10}$ A Lei de Diretrizes e Bases da Educação Brasileira (Brasil, 1996) define como modalidades educativas: EaD, EJA, educação profissional (Brasil, 1996, Art. 39 a 42); educação especial (Brasil, 1996, Art. 58 a 60); indígena (Brasil, 1996, Art. 32, Art. 35-A e 79) e quilombola (Brasil, 1996, Art. 26A). Ver também Libâneo, Oliveira e Toschi (2012, p. 235-237, p. 361-370). EaD: Educação a Distância (Brasil, 1996, Art. 80). EJA: Educação de Jovens e Adultos (Brasil, 1996, Art. 37 e 38). 
educacional pode se dar em um contexto formal ${ }^{11}$ - ou seja, em um contexto no qual a figura do estudante e do professor está claramente delineada -, contendo um conteúdo elegido, processos metodológicos de ensino, avaliação e certificação (aqui inclusas a educação básica, técnica e superior e pós-graduação). Outra identificação para esta categoria seria o ensino informal, que se dá em contextos extraescolares, e ainda o ensino específico de música, que também ocorre em contexto formal, porém predominantemente voltado ao ensino musical.

No Gráfico 6, observamos que na pesquisa doutoral predomina o ensino formal, que, no caso, abrange vários niveis e contextos. Posteriormente comparece o ensino específico de música, envolvendo majoritariamente o ensino de instrumento musical ou de canto. No caso, essas 220 teses abordam temáticas ligadas aos processos de ensino-aprendizagem.

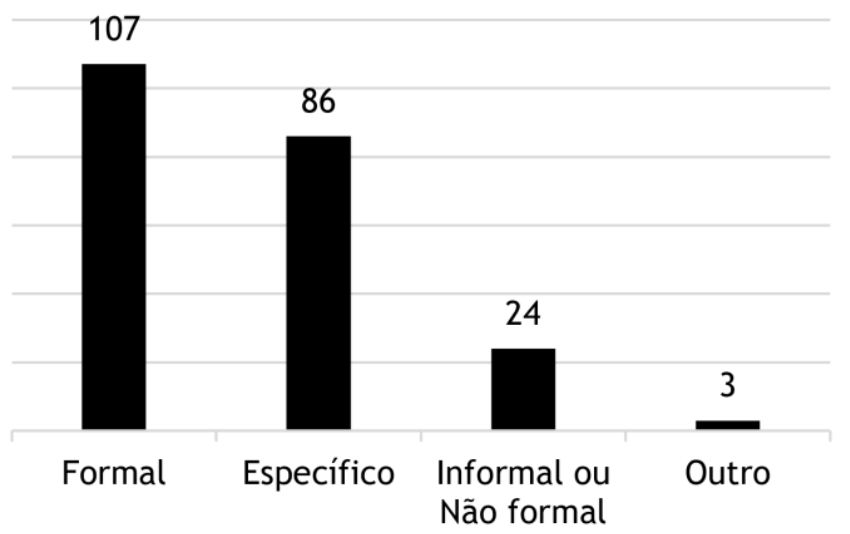

Gráfico 6: Teses por ambiente educativo (Formulário 1). Fonte: Elaborado pelo autor. Análise de dados da investigação junto às 300 teses.

O Gráfico 7 apresenta o interesse das teses que abordam ensino/aprendizagem por tipos de "modalidades educativas", com o ensino presencial em destaque. Não foram encontradas teses que abordam a educação musical quilombola, e apenas uma tese abordando o contexto indígena.

\footnotetext{
${ }^{11}$ Sobre educação formal, informal e não formal: Libâneo, Oliveira e Toschi (2012, p. 235-237).
} 


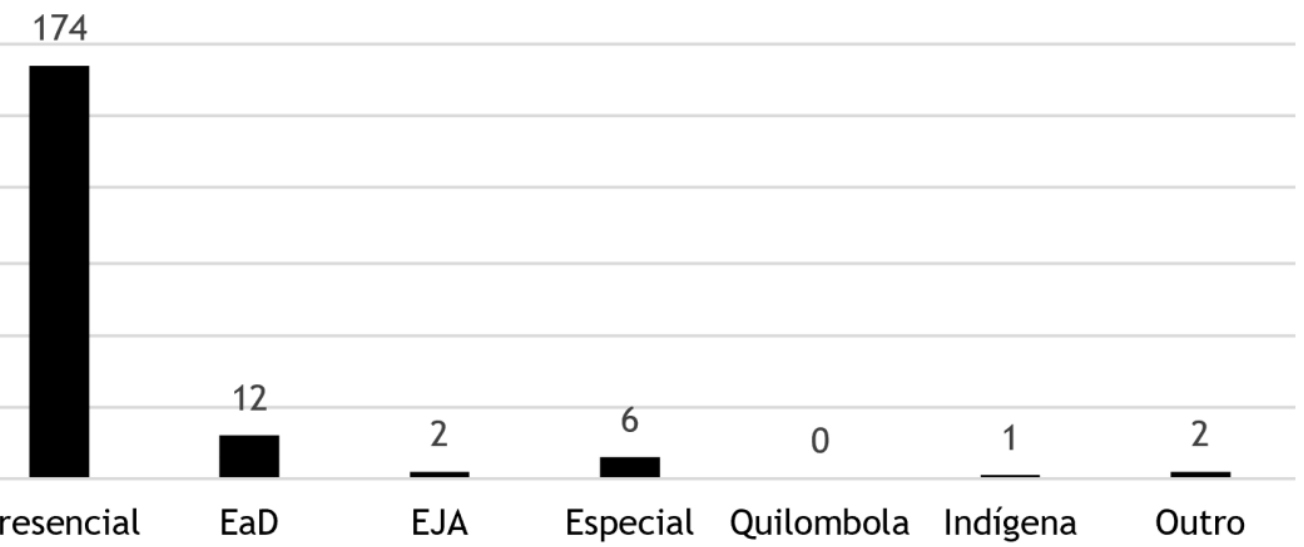

Gráfico 7: Teses por modalidade educativa (Formulário 1). Fonte: Elaborado pelo autor. Análise de dados da investigação junto às 300 teses.

No Gráfico 8 é possivel observar que a maioria das teses que estudam questões relacionadas ao ensino/aprendizagem musical aborda majoritariamente o ensino superior, seguido pela educação básica no ensino fundamental e pela educação infantil (também pertencente à educação básica, mas oficialmente subdividida em três níveis: infantil, fundamental e médio).

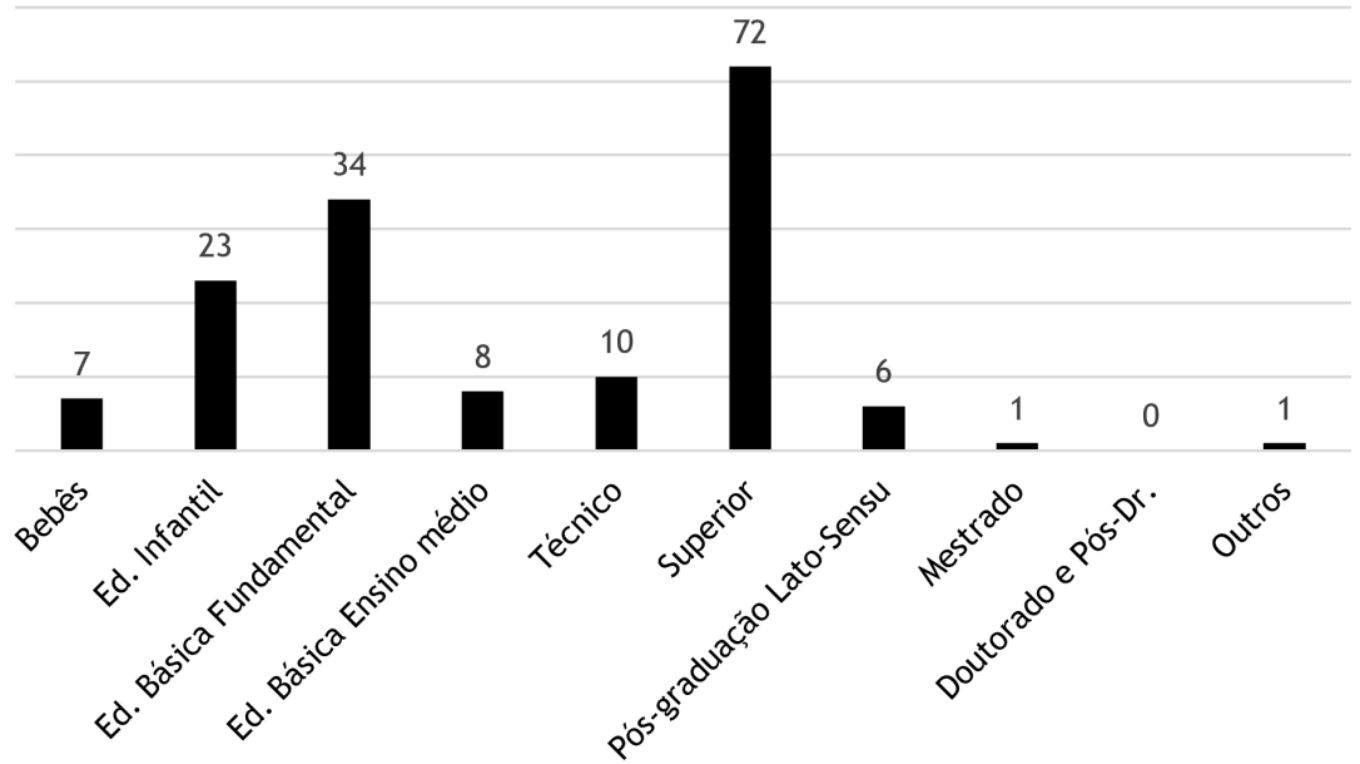

Gráfico 8: Teses por nível de ensino (Formulário 1). Fonte: Elaborado pelo autor. Análise de dados da investigação junto às 300 teses.

O Gráfico 9 apresenta a distribuição por linhas investigativas, as mesmas identificadas na classificação feita em artigos de revistas científicas 
brasileiras $^{12}$. Esta classificação temática identifica quais o interesse dos pesquisadores, sendo as cinco linhas mais investigadas: formação de professores, ensino da performance, escola de ensino básico, história da educação musical e multiculturalismo.

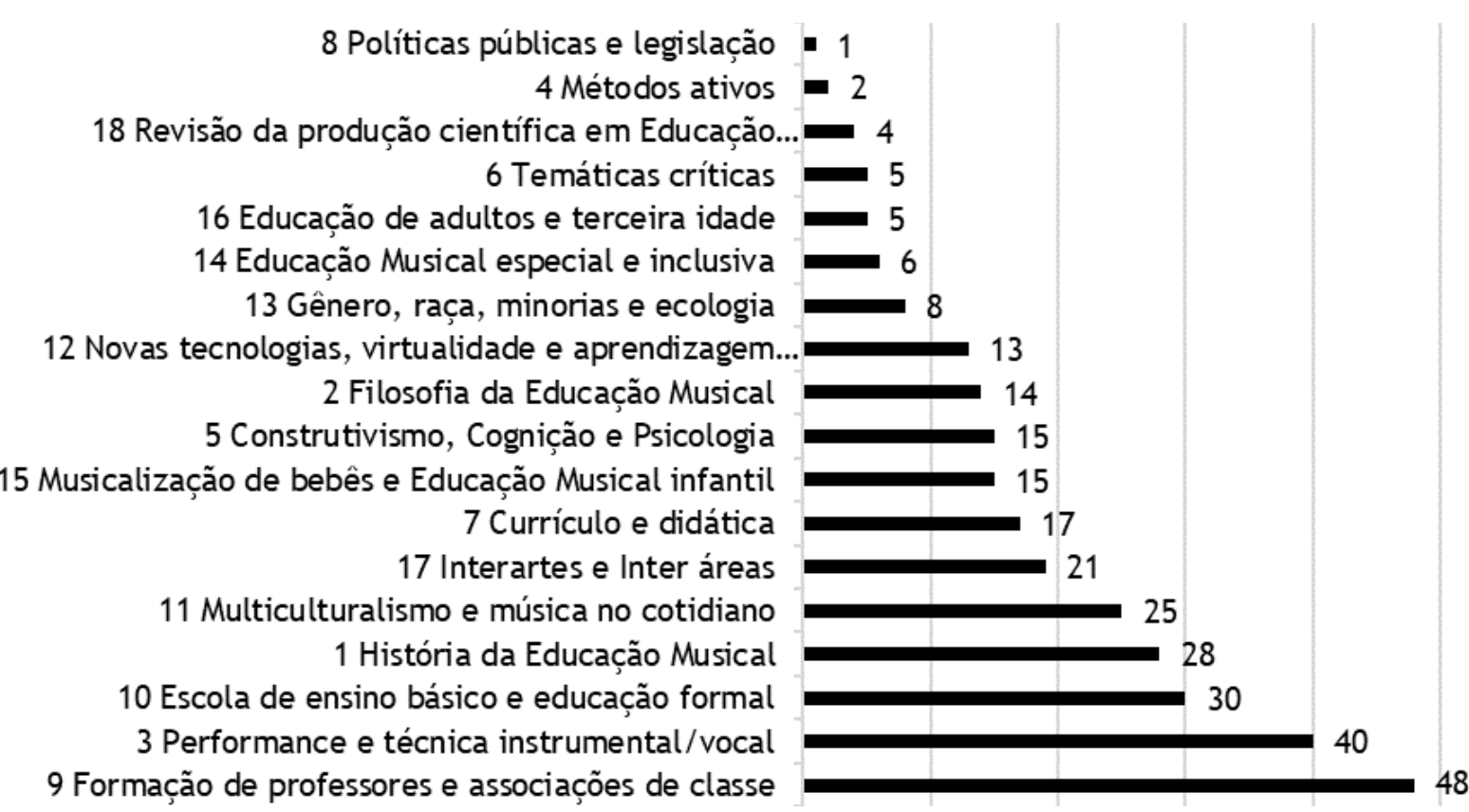

Gráfico 9: Quantitativo de teses por linhas investigativas (Formulário 1).

Fonte: Elaborado pelo autor. Análise de dados da investigação junto às 300 teses.

Como mostra o Gráfico 10, as categorias mais codificadas em todas as fontes, para os Formulários 2(e) e 2(i) foram: "estrutura e funcionamento de organizações escolares" com foco nos processos educativos. Apesar de estas duas categorias serem apresentadas juntas em um único gráfico, elas foram codificadas separadamente, uma por vez, para todas as 296 teses analisadas.

\footnotetext{
12 No relatório original da investigação, há um capítulo onde são analisadas as temáticas dos artigos da área publicados no Brasil (Pereira, 2019).
} 


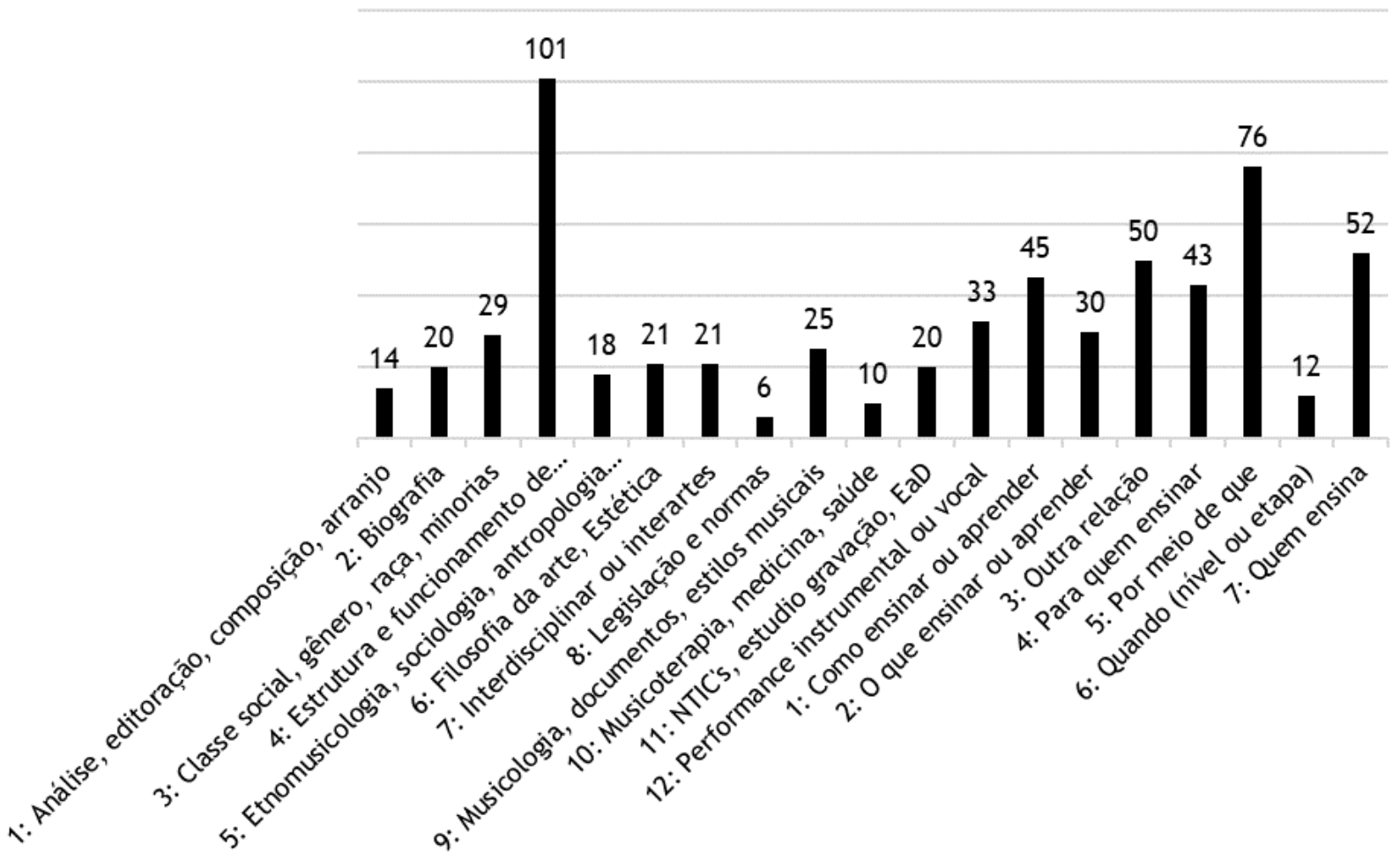

Gráfico 10: Codificação geral para os Formulários 2(e) e 2(i) - contexto extrinseco e intrínseco ao processo ensino-aprendizagem. Fonte: Elaborado pelo autor. Análise de dados da investigação junto às 300 teses.

O Gráfico 11 mostra a codificação dos subtemas da educação musical (Formulário 3) para todas as teses, nas quais comparece em maior número a pesquisa sobre formação e prática de professores de música.

Levando em conta que 48 pesquisas foram identificadas abordando a temática sobre formação de professores, outras oito teses ainda apresentam relação com este grupo. Em segundo lugar comparecem os estudos sociológicos que destacam os aspectos sociais nas investigações, e, com número igual, a pesquisa sobre cognição, psicologia e desenvolvimento.

Assim, podemos confirmar as indicações de Figueiredo (2010) sobre fases da pesquisa em educação musical desde o início do século XX até a atualidade: 1) inicialmente temos interesse por estudos da história e instrumento musical; 2) posteriormente temos interesse da pesquisa por questões relacionadas à cognição, psicologia e desenvolvimento; 3) e, por fim, na atualidade o interesse tem se dados mais acentuadamente sobre questões abordadas desde o prisma da sociologia. 


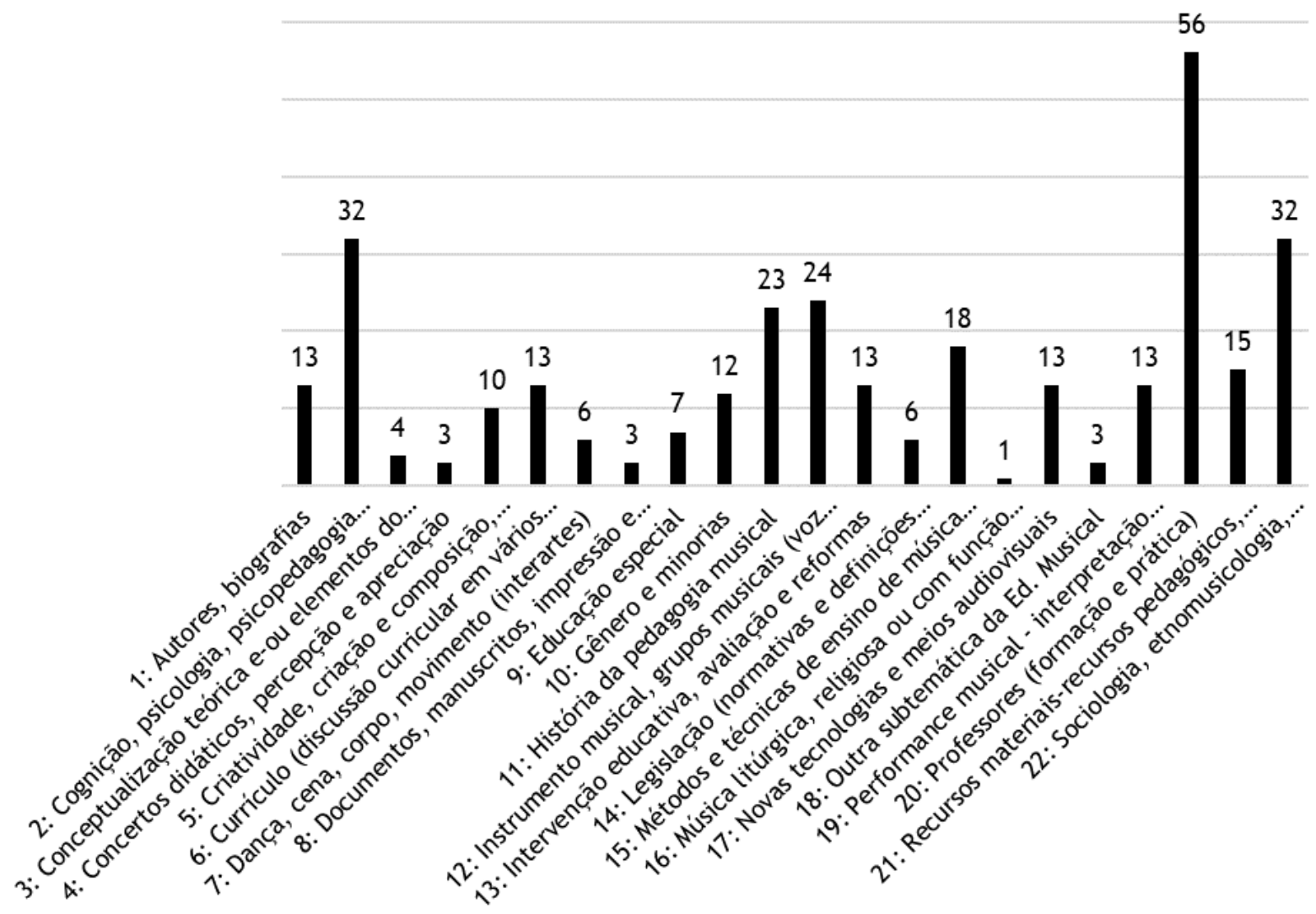

Gráfico 11: Codificação geral para o Formulário 3 - subtemas da educação musical. Fonte: Elaborado pelo autor. Análise de dados da investigação junto às 300 teses.

O Gráfico 12 mostra a codificação geral das teses para as didáticas da educação musical (Formulário 4: Didáticas musicais), que apresenta acentuado número para a abordagem "contextualista, culturalista, pósmoderna", e, em segundo lugar, para a "metodológica", fazendo, esta última, referência a métodos de ensino de instrumento ou canto. 


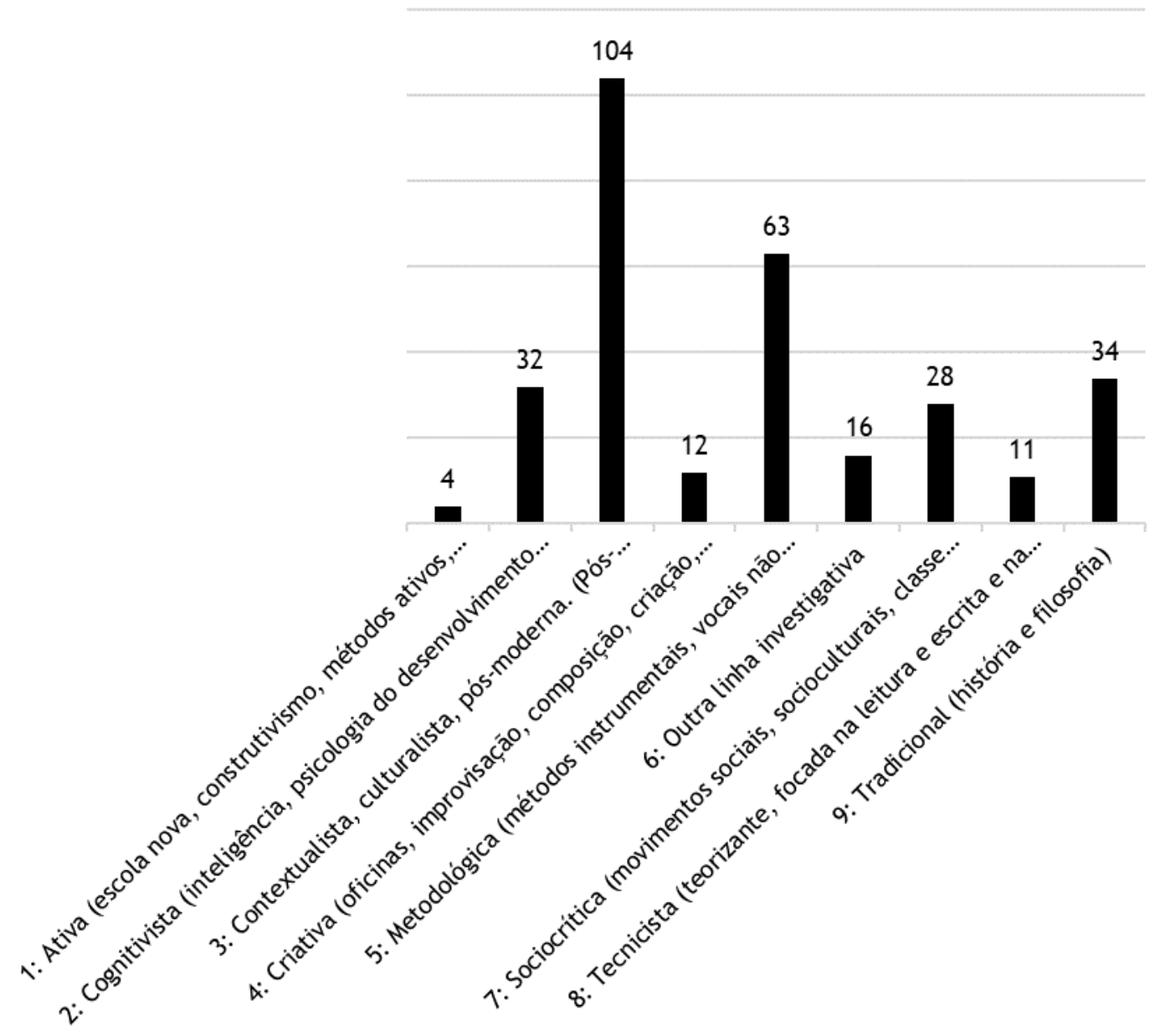

Gráfico 12: Codificação geral para a Formulário 4 - didáticas musicais. Fonte: Elaborado pelo autor. Análise de dados da investigação junto às 300 teses.

É possivel sintetizar alguns pontos principais relacionados às análises realizadas junto a este grupo de teses defendidas de 1989 até 2017:

- Das 300 teses listadas, 296 foram analisadas;

- O processo de busca se deu com acesso aos arquivos digitais via web;

- Mais de $60 \%$ das teses analisadas foram desenvolvidas por mulheres;

- Não há diferença entre o nivel de divulgação científica oriunda da tese entre os gêneros masculino e feminino, porém a questão de gênero comparece em relação às temáticas;

- Foram identificados três niveis de incremento de produção doutoral: até o ano 1999, de 2000 até 2008 e de 2009 até 2017;

- As teses da área da educação musical foram desenvolvidas majoritariamente nos programas de Pós-Graduação em Música e 
Educação, e as demais áreas aparecem em quantidade bem menor, porém amplamente diversificadas;

- As universidades públicas das regiões Sul, Sudeste e Nordeste são as que mais ofertam e produzem o doutoramento em educação musical;

- Relativo às linhas investigativas, as três linhas mais estudadas são "formação de professores", "ensino de instrumento ou canto", "educação musical na educação básica" e "história da educação musical";

- A educação formal superior comparece como predominante nas teses que estudam a relação ensino/aprendizagem. Posteriormente, aparece o interesse pelo ensino específico de música (instrumento ou canto);

- Ainda há ambientes, modalidades e níveis de ensino que não foram pesquisados, como a educação musical quilombola e indigena (esta última aparece em uma única tese).

Entre as principais características descritivas, destacam-se: a) a classificação das teses por informações quantitativas de suas identificações e propriedades; b) a compreensão de que os estudos da área podem ser constituídos em contextos extrínsecos e intrínsecos ao processo de ensinoaprendizagem e às características destes estudos em cada especificidade; c) a identificação de niveis, modalidades e ambientes de ensino e a abertura da possibilidade de uma comparação destas características com categorias temáticas e conceituais.

Após estas análises, verificou-se que o foco da maioria dos estudos de doutoramento em educação musical no Brasil está sobre a estrutura e o funcionamento de organizações escolares e ainda sobre processos educativos, projetos e programas de ações educativo-musicais em vários contextos, mas principalmente no contexto do ensino específico de música (ensino de instrumento ou canto), cuja temática é de maior interesse do que a temática do ensino de música no contexto da educação básica. Vale ressaltar que, entre as didáticas da área, as abordagens contextualistas e multiculturalistas compareceram na maioria das teses, além das abordagens sobre diferentes metodologias de ensino de música, e ainda, em menor número, sobre cognição.

\section{CONCLUSÃO}

Sintetizamos os resultados alcançados neste estudo, no qual foi possivel desenvolver:

- Identificação da disponibilidade e acessibilidade da produção doutoral; 
- Apresentação da evolução da produção doutoral brasileira de 1989 até 2017;

- A distribuição geográfica da produção doutoral brasileira;

- Um estudo reflexivo sobre o impacto das teses na divulgação científica da área;

- A confirmação dos campos de produção das teses: Música e Educação;

- A identificação das universidades brasileiras que mais produzem teses na área;

- A distribuição das modalidades, ambientes e niveis educativos pesquisados;

- A identificação dos temas e das linhas investigativas mais pesquisadas nas teses;

- A identificação dos subtemas mais e menos pesquisadas nas teses;

- A identificação das didáticas musicais presentes nas teses da área;

- A classificação das teses por abordagens intrínsecas e extrínsecas ao processo ensino-aprendizagem;

- O desenvolvimento de várias comparações entre as categorias descritivas.

Entre as principais indicações e proposições advindas desta investigação, podemos sintetizar: a) a criação de grupos de investigação para estudo e reflexão sobre a pesquisa na própria área; b) a ampliação da investigação sobre educação musical envolvendo a participação coletiva de professores e investigadores; c) a intensificação de investigações de revisão da produção científica da área; d) a consideração pelo contexto acadêmico das linhas investigativas historicamente constituídas nas pesquisas da área.

Esta investigação, além de apresentar dados descritivos e de possibilitar uma análise e reflexão social junto às teses da área da educação musical do Brasil, apresenta três produtos como resultados da pesquisa. Estes produtos servem como referências para novos estudos e investigações, facilitando o acesso à produção científica em educação musical do Brasil. O primeiro produto é mais ilustrativo, o segundo é propositivo, e o terceiro produto é mais descritivo:

1. Cartografias da pesquisa em educação musical no Brasil;

2. Indicações de critérios de análise da pesquisa em educação musical;

3. Índices e catálogo de teses brasileiras sobre educação musical;

Disponíveis em: www.sites.google.com/view/educacaomusicalnobrasil. 
Espera-se que esta descrição geral sobre a situação da investigação doutoral em educação musical do Brasil, juntamente com as proposições e recomendações originadas desta produção, e com os produtos gerados, possam colaborar com o desenvolvimento da educação musical como área de conhecimento cultural, científico e pedagógico.

\section{REFERENCIAS}

APA. Que es el estado del arte. Associação de Psicologia Americana, Espanha, [s. d.]. Disponivel em: http://normasapa.net/que-es-el-estadodel-arte. Acesso em: dez. 2017.

ARAÚJO, K. da S. R.; TOSCANO, C. As pesquisas em educação musical no período de 2001 a 2102. In: SEMINÁRIO INTERNACIONAL DE REPRESENTAÇÕES SOCIAIS, SUBJETIVIDADE E EDUCAÇÃO, 2.; SEMINÁRIO INTERNACIONAL SOBRE PROFISSIONALIZAÇÃO DOCENTE, 4., 2013, Curitiba. Anais [...]. Curitiba, 2013. p. 31232-31245.

BARDIN, L. Análise de conteúdo. São Paulo: Edições 70, 2011.

BAUER, M. W.; GASKELL, G. Pesquisa Qualitativa com texto, imagem e som: um manual prático. 11. ed. Petrópolis: Vozes, 2013.

BRASIL. Lei $n^{\circ}$ 9.394, de 20 de dezembro de 1996. Lei das Diretrizes e Bases da Educação nacional. Estabelece as diretrizes e bases da educação nacional. Brasília, DF, 1996. Disponível em:

http:// portal.mec.gov.br/arquivos/pdf/ldb.pdf. Acesso em: dez. 2016.

COOPER, H. Research Synthesis and Meta-Analysis: a step-by-step approach. 4. ed. San Antonio: Sage, 2000.

COOPER, H.; HEDGES, L. V.; VALENTINE, J. C. The Handbook of Research Synthesis and Meta-Analysis. New York: Russel Sage Foundation, 2009.

DEL-BEN, L. M. A delimitação da educação musical como área de conhecimento: contribuições de uma investigação junto a três professores do ensino fundamental. Em Pauta, v. 12, n. 18/19, p. 65-93, 2001.

- (Para)Pensar a pesquisa em educação musical. Revista da Abem, v. 24, p. 25-33, 2010.

Modos de pensar a educação musical escolar: uma análise de artigos da revista da ABEM. Inter Meio, v. 37, n. 19, p. 125-148, 2013.

FERNANDES, J. N. Pesquisa em educação musical: situação do campo nas dissertações e teses dos cursos de Pós-Graduação Stricto Sensu em Educação. Revista da Abem, v. 5, p. 45-57, 2000. 
Pesquisa em educação musical: situação do campo nas dissertações e teses dos cursos brasileiros (II). Revista da Abem, v. 16, p. 95-98, 2007. . Educação musical: temas selecionados. Curitiba: CRV, 2013.

FIGUEIREDO, S. L. F. de. Considerações sobre a pesquisa em educação musical. In: FREIRE, V. L. B. (Org.). Horizontes da Pesquisa em Música. Rio de Janeiro: 7 Letras, 2010. p. 155-175.

FRANCO, M. L. P. B. Análise de conteúdo. Brasília: Líber Livro, 2012.

GILLANDERS, C.; MARTÍNEZ CASILLAS, P. La investigación en el ámbito musical. Música y educación: Revista trimestral de pedagogía musical, v. 64, p. 85-104, 2005.

GLASS, G. V. Primary, secondary, and meta-analysis of research.

Educational Researcher, v. 5, n. 11, p. 3-8, 1976. Disponível em: http://www.jstor.org/stable/1174772.

HEMSY de GAÍNZA, V. La educación musical en los tiempos ecológicos. In: BENENZON, Rolando. La nueva musicoterapia. Buenos Aires: Lumen, 1998. p. $153-158$.

HUNTER, J. E.; SCHMIDT, F. L. Methods of Meta-Analyses: correcting error and bias in research findings. London: Sage, 2004.

KRAEMER, R. D. Dimensões e Funções do Conhecimento PedagógicoMusical. Em Pauta, v. 11, n.16/17, p. 48-73, 2000.

LIBÂNEO, J. C.; OLIVEIRA, J. F. de; TOSCHI, M. S. Educação escolar: políticas estrutura e organização. 10. ed. rev. e ampl. São Paulo: Cortez, 2012.

LONDOÑO PALACIO, O. L.; MALDONADO GRANADOS, L. F.; CALDERÓN VILLAFÁÑEZ, L. C. Guía para construir estados del arte. Bogotá:

International Corporation of Networks of Knowledge, 2014. Disponivel em: http:/ /iconk.org/docs/guiaea.pdf. Acesso em: set. 2018.

LÓPEZ, A. D.; MOTA, A. Saberes cientificos humanisticos y tecnológicos: procesos de enseñanza y aprendizaje. Investigación Educativa en México (1992-2002). México: COMIE, 2003.

LOUREIRO, A. M. A. O ensino de música na escola fundamental. Campinas: Papirus, 2003.

A educação musical como prática educativa no cotidiano escolar. Revista da Abem, v. 10, p. 65-74, 2004.

LOVATTO, P. A. et al. Meta-análise em pesquisas científicas: enfoque em metodologias. Revista Brasileira de Zootecnia, v. 36, p. 285-294, 2007. 
MACIAS-CHAPULA, C. A. O papel da informetria e da cienciometria e sua perspectiva nacional e internacional. Ciência da Informação, v. 27, n. 2, p. 134-140, 1998.

MATEIRO, T. D. A. N. Educação musical nas escolas brasileiras: retrospectiva histórica e tendências pedagógicas atuais. Nupeart - Núcleo Pedagógico de Educação e Arte, v. 4, n. 4, p. 115-135, 2006.

MORAES, Zeny O. de. Psicogênese do som e do ritmo a luz da teoria do desenvolvimento de Jean Piaget: um estudo de caso. Tese (Doutorado em Educação) - Universidade Federal do Rio Grande do Sul, Porto Alegre, 1989. Disponivel em: https://lume.ufrgs.br/handle/10183/182087. Disponivel em: out. 2018.

ORIOL de ALARCÓN, N. Temáticas de tesis doctorales de música em España (1978-2011). Música y Educación, v. 92, año XXV, p. 58-94, 2012.

PEREIRA, E. P. R. Pesquisas de Estado da arte na Educação, na Música e na Educação musical. In: SEMINÁRIO NACIONAL DE PESQUISA EM MÚSICA DA UFG, 17.; SEMINÁRIO NACIONAL FLADEM, 1., 2017, Goiânia. Anais [...]. Goiânia, 2017. p. 1-14. Disponivel em: https: / / mestrado.emac.ufg.br/n/31464-sempem-anais-on-line. Acesso em: out. 2017.

PEREIRA, E. P. R. A educação musical no Brasil: temáticas, concepções e linhas investigativas. 2019. 513 f. Tese (Doutorado em Educação) Universidade de Santiago de Compostela, Santiago de Compostela, 2019.

PIRES, N.; DALBEN, Â. I. L. de F. Música nas escolas de educação básica: a produção acadêmica dos cursos de Pós-Graduação Stricto Sensu no Brasil (1972-2011). Opus: Revista Eletrônica da Anppom, v. 19, n. 2, p. 171-208, 2013.

RODRIGUES, C. A Abordagem processual nos estudos da tradução: uma meta-análise qualitativa. Cadernos de Tradução, v. 2, n. 10, p. 23-57, 2002. Disponivel em:

http:/ / 150.162.1.115/index.php/traducao/article/download/6143/5701. Acesso em: ago. 2017.

SOUZA, R. C. C. R. de; MAGAlHÃES, S. M. O. (Orgs.). Pesquisas sobre professores: métodos tipos de pesquisa, temas, ideário pedagógico e referenciais. Goiânia: Editora da PUC Goiás, 2011.

TOMÁS, L. A pesquisa acadêmica na área de Música: um estado da arte (1988-2013). Vol. 1. Série Pesquisa. Porto Alegre: Anppom, 2015.

URSO JUNIOR, J. Stress e personalidade: “overview” e avaliação crítica de revisões sistemáticas sobre padrão comportamental tipo A e personalidade tipo D com desfechos coronarianos. Tese (Doutorado em Psicologia) Universidade de São Paulo, São Paulo, 2011. 
WEISS, E. El campo de la investigación educativa en México a través de los estados de conocimiento. Conferencia pronunciada en el VIII cine. Hermosillo, México, 2005.

VOSGERAU, D. S. R.; ROMANOWSKI, J. P. Estudos de revisão: implicações conceituais e metodológicas. Revista Diálogo Educacional, v. 14, n. 41, p. 165-189, 2014.

Eliton Perpétuo Rosa Pereira é Doutor em Ciências da Educação pela Universidade de Santiago de Compostela (USC-Espanha). Licenciado e mestre em Música pela Escola de Música e Artes Cênicas da Universidade Federal de Goiás (Emac/UFG). Especialista em Tecnologias em Educação (PUC-Rio). No Instituto de Educação, Ciência e Tecnologia de Goiás (IFG-Brasil), atua na Licenciatura em Música - Campus Goiânia. Tem experiência em educação musical, canto coral, metodologia científica e formação de professores. http://orcid.org/0000-0002-9181-2543

Carol Gillanders é Ph.D. Desde 2000 é professora de educação musical na Faculdade de Educação da Universidade de Santiago de Compostela. É membra do grupo de pesquisa em Tecnologia Educacional liderado pela Dra. Beatriz Cebreiro e trabalhou em vários projetos europeus. Seus interesses de pesquisa incluem aprendizado de serviço, projetos de arte interdisciplinares e TIC. É coautora de um guia para professores que acompanham músicas, além de diversos artigos relacionados à educação musical. http://orcid.org/0000-0001$\underline{7122-5416}$ 